\title{
The Community-Based Information Infrastructure of Older Adult Digital Learning
}

\author{
A Study of Public Libraries and Senior Centers \\ in a Medium-sized City in the USA
}

\author{
Noah Lenstra
}

\begin{abstract}
In the United States of America, senior centers and public libraries are ubiquitous social institutions found in virtually every municipality. This article analyses these institutions as community-based information infrastructure in the digital learning practices of older adults. Older adults turn to these institutions to learn technology in retirement. How learning takes place in these spaces is shaped both by the institutions, and by the older adults. Negotiations between institutions and older adults shape digital learning. These negotiations are shaped by societal ageism. This article shows that older adults are not passive participants in technology learning, using services provided for them by others, but instead actively shape both how learning services are proffered and the institutional contexts in which these services exist. By learning to embrace the agency of older adults, these under-funded public institutions could powerfully reconfigure themselves for an information society that is also ageing.
\end{abstract}

Keywords: community informatics, library and information science, infrastructure studies, older adults, public libraries, senior centers

\section{Introduction}

In the popular press (and even in the scholarly literature) the digital literacy of older adults is often understood in relation to their supposedly declining minds and bodies. That is, age-related disabilities orient the discourse on older adults and digital technology (see discussions of this topic in Bowen 2012, Gurstein 2012). This study instead focuses on the digital learning practices of older adults in the context of the local communities where older adults live. Just as it proverbially 'takes a village to raise a child', it may likewise take a local community to support people as they learn, practice, and expand digital literacy as they age.

This study started with the hypothesis that community support is important for the digital literacy of older adults. By drawing upon the theory of information infrastructure to investigate this hypothesis, this study in fact found that the community-based infor- 
mation infrastructure of older adult digital literacy is instead shaped by negotiations and social struggle. In other words, older adults are not passive recipients of support services created for them by other members of their communities. Instead, they actively shape the community-based information infrastructure that they and others participate in throughout the course of daily life.

To introduce and discuss this finding, this article begins by discussing senior centers and public libraries as a type of community-based information infrastructure involved in the digital learning practices of some older adults in the United States. The methods of this ethnographic inquiry are then introduced. The findings from this study illustrate how community-based information infrastructure is shaped by older adults learning technology, as well as by the staff and volunteers who work in these institutions. These findings are illustrated through the stories of incidents documented during this study, as well as through an in-depth case study of a representative institution. This article concludes with a discussion of how understanding community-based information infrastructure contributes to our understanding of ageing communities in our digital world.

\section{Literature review}

Older adults that seek support learning technology turn to multiple sources. Past research shows that many older adults rely on family members (e.g. Bowen 2012, Selwyn 2004). Other older adults turn to groups and institutions in their local communities. Summarising the findings from the Sus-IT project in England and Scotland, Hardill (2014: 280) writes that:

Sustaining digital engagement is linked to the significant, indispensable and crucial ICT support role of (extended) family members .... But not all older adults received the help and support needed to become confident users from family members, and for such older adults support from the community, often involving young people, organized formally by neighborhood and community groups is providing a vital resource supporting older people sustain their use of digital technologies. (emphasis added)

This finding, and others like it found in studies from Jamaica (Bailey \& Ngwenyama 2011), Spain (Sayago \& Blat 2010), China (Xie 2005), and the U.S. (Bowen et al. 2014), suggest that groups and institutions in local communities play important roles in the digital learning practices of older adults.

In the United States of America (U.S.), public libraries and senior centers are locally funded institutions that provide services to older adults. The research literature on the roles of these institutions in relation to digital learning among older adults finds that although many institutions do provide some sort of support services, the efficacy of these services has been mixed (Bennett-Kapusniak 2013, Gardner et al. 2012, McKee $\&$ Blair 2006, Perry 2014). Nonetheless, the potential of these institutions to support the digital learning of older adults is immense. These institutions are found in municipalities and urban areas throughout the U.S. Now numbering over 11,400 across the country (National Council on Aging 2014), senior centers have been described as 'the one community institution that our independent elderly can identify as theirs' (Cohen 2003: ix). There are also 16,536 public libraries throughout the U.S. (American Library Association 
2015). Over the last decade many public libraries have adjusted their services to meet the needs of their ageing communities (Schull 2013).

To better understand these institutions in relation to the digital learning practices of older adults, this study draws on the theory of information infrastructure. Theories of information infrastructure foreground the interplay between, and mutual shaping of, information systems and information users (Guribye 2015, Star 1999). This theory has many parallels to theories in media and communication (Oudshoorn \& Pinch 2003) and in social informatics (Lamb \& Kling 2003) that analyse how technology users play active roles in shaping the technologies they use.

Information infrastructure is 'a fundamentally relational concept, becoming real infrastructure in relation to organized practices' (Star 1999: 380). Information infrastructure consists of information systems integrated into the practices of groups of people. This integration sometimes involves negotiation and struggle. For instance, in their analysis of a natural history museum as a type of information infrastructure, Star and Griesemer (1989: 388) discuss the museum as an information infrastructure shaped by negotiations involving multiple actors, including 'professional scientists, amateur naturalists, patrons, hired hands and administrators'. The backwoods trappers (the hired hands) who captured the specimens displayed at the museum had a different agenda than the scientists, who in turn had different agendas than the museum's funders and visitors. The negotiations of these different agents, manifested in their social practices, contributed to the museum's emergence and evolution over time. This example illustrates how information infrastructure is shaped by the disparate social practices of the different groups of people that, in various ways, participate in the infrastructure. Bowker calls the process of making the information infrastructure of social practices visible through empirical scholarship an 'infrastructural inversion' (Bowker 1994: 10). Social practices are inverted to understand how infrastructure supports them, and how this infrastructure emerges and evolves over time through the actions of disparate groups of people (Bowker \& Star 1999).

While this theory has been widely used to understand how corporations and science function, less attention has been directed to the information infrastructure of daily life (Edwards et al. 2009: 364). In particular, the relationship between information infrastructure and the digital learning practices of older adults has not been analysed. This lacuna suggests that an infrastructural inversion of the digital learning practices of older adults could add to our understanding of this phenomenon.

\section{Method}

To analyse the information infrastructure of older adult digital learning, this study utilised a case study approach to ethnography. The primary technique used in this study was participant observation. Since Suchman's (1987) canonical work on situated action, scholars have found that in-depth and up-close analyses of how people use technology in naturalistic social settings reveal important information about how technology is incorporated into work and life. Discoveries made with this method are not possible to arrive at through other methods (Blomberg \& Karasti 2013).

I studied three senior centers and three public libraries in a medium-sized urban area in the Midwest. I focused attention on technology support services in these institutions. The specific methods used were: 467.5 hours of participant observation (i.e. 
ethnographic fieldwork) in 267 technology support sessions with 209 older adults at public libraries and senior centers; 54 semi-structured interviews with older adults who participate in these services; 7 interviews with staff responsible for these services; and a review of institutional documents. Data collection occurred from September 2014 to August 2015. ${ }^{1}$ The multiple methods used in this study were chosen in order to document and analyse the large and complex community-based information infrastructure involved in the digital learning practices of older adults. The actors involved in this infrastructure include: older adults, ${ }^{2}$ public librarians, senior center staff, volunteers (including university students), the administrators and funders of these institutions, the digital technologies present at these institutions (which change over time, and include devices brought to the institutions by older adults), and the programs offered at these institutions for individuals seeking assistance with technology.

The administrators of these institutions allowed me to conduct research there because I offered services to them. Similarly, older adults allowed me to study them because I was serving both them and their communities. At the three public libraries, I participated in technology volunteer programs managed by librarians. At the senior centers, I helped staff administer drop-in computer classes. Individuals self-selected to participate in fieldwork. The sample consists of older adults who in the course of daily life come to senior centers and public libraries. The fact that 209 older adults participated in this study suggests that many older adults come to these institutions to find support learning digital technology.

My position within these institutions impacted what data could could be gathered. My perspective was that of a service provider. As such, some of the older adults that participated in this study may have adapted their actions because they sought my services. It is possible that if I occupied a different role within these institutions (such as a seeker of services, or a neutral external party), I would have had different interactions, and thus different data. I attempted to compensate for this limitation by supplementing ethnographic fieldwork with semi-structured interviews, in which I invited older adults to reflect on and discuss their learning practices in relation to the institutions. Through these multiple sources of data, I analysed these institutions as examples of communitybased information infrastructure involved in the digital learning practices of older adults.

\section{Findings}

This study began with the hypothesis that community support is important for the digital literacy of older adults. During the course of data collection, however, I found that the community-based information infrastructure of public libraries and senior centers is shaped by older adults, as well as by the staff and volunteers who work in these institutions. In other words, community-based information infrastructure is a negotiated product, shaped by the differing agendas of different agents. On the one hand, this study confirmed that community support is indeed important for the digital literacy of older adults. On the other hand, this study showed that this support is shaped in the context of negotiations and social struggles over resources. These negotiations are further shaped in the context of societal ageism, which affects how both institutions and older adults themselves frame digital literacy and learning. 


\section{Older adults shape senior centers and public libraries}

Older adults actively shape senior centers and public libraries, and have done so for decades. Older adults lead community groups affiliated with senior centers and public libraries, such as 'friends of the library' groups and community advisory committees. Through leadership in these groups, older adults contribute to the continued vitality of these community spaces. This point is particularly true in senior centers. Senior center budgets are small fractions of public library budgets. Since they have less funds, senior centers rely on the organised volunteerism of older adults to continue to exist across time.

As publicly funded institutions, both public libraries and senior centers are at risk of losing their funding in the context of the privatisation of social services in the U.S. (D'Angelo 2006). In this context, the volunteer leadership provided to senior centers and public libraries by older adults sustains these institutions over time. In other words, older adults not only come to these spaces to learn technology. They also lead these spaces, which have played important roles in their lives and in their communities throughout time. Nonetheless, this leadership role is not always respected or even acknowledged by the administrators of these sites. This is particularly so in the context of digital technologies, where older adults are bypassed in decisions about how to incorporate technology into these institutions.

A detailed narrative of one of the institutions studied illustrates these findings. The activism of a group of older adults in the 1960s and 1970s led to the foundation of the Tubman Senior Center. ${ }^{3}$ This group of older adults called themselves the 'Tubman Seniors' because they met regularly at the Tubman Community Center. In the early 1970s, they started electing officers and holding business meetings. The Tubman Seniors organised events for themselves, such as monthly trips to the grocery store, crafts, and cultural programs. They also organised events for their community. As the Tubman Seniors grew in size, they struggled for a space of their own. Beginning in 1971, the group pressured the local government to fund a senior center. This activism led to the founding of the Tubman Senior Center in 1978. The local government and the Tubman Seniors community group jointly administer the senior center.

In relation to digital technology, however, the Tubman Seniors have been alienated from the management of the Tubman Senior Center. As digital technology has become incorporated into the senior center, its paid staff have turned to external entities for support. Older adults have not been involved in the administrative decisions about how to incorporate digital technology into the senior center. Instead, the primary partner in these projects has been a local university. In the mid-1990s, local university students installed four desktop computers at the senior center. Since then, students from the university have come intermittently to the senior center to assist Tubman Seniors learning technology.

The installation of wireless internet (wifi) in the senior center also bypassed the Tubman Seniors. The wifi was installed in 2010 as part of a municipal broadband expansion project that received federal funding. When the wifi was installed at the senior center, none of the Tubman Seniors were aware of its existence. The local government did not work with the Tubman Seniors to ensure they could use the wifi. It was not until 2014 that the Tubman Seniors started using the wifi.

Nevertheless, the Tubman Seniors actively struggle to shape how digital technology operates in their senior center. For instance, in 2012 the Tubman Seniors organised to 
increase the number of computer classes at the senior center. The Tubman Seniors also struggle to reconfigure their computer lab. When the university students installed the new computers, they did not install a printer. A group of quilters that met regularly at the center decided to install a printer in the computer lab. Unfortunately, this accomplishment was not supported by the staff of the senior center. When the printer stopped working, the staff refused to support it because it was not owned by the local government. Another Tubman Senior offered to donate a printer he had at his house, but the staff would not provide him with the technical access he needed to install the printer in the computer lab. Through these types of struggles, digital technology becomes incorporated into community-based information infrastructure.

\section{Digitallearning emerges in and through community-based information infrastructure}

Having analysed this community-based information infrastructure from an institutional perspective, this article now shifts the focus to the perspective of older adults learning technology. Over time, the digital learning practices of the older adults studied have intersected with the community-based information infrastructure of public libraries and senior centers. This finding receives illustration in the story of Hester, an 89-year-old African American who has lived her entire life in the local community. Hester started using digital technology in the 1960s, when she was employed as a stenographer in a courthouse. There she used a mainframe computer to input data on court cases. She received computer training from faculty at a local university.

In the 1980s, and in particular when she retired in 1986, Hester struggled to maintain her digital literacy skills. She said that in the 1960s she:

Learned how to wire a mother board! ....But I lost track of [computers] when they switched from mainframes to PCs. I quit using all of that when I retired.

Interviewer: When did you start up again with digital technology?

Hester: Well, I took a course on the PC in the, I can't remember when, sometime in the early ' 80 s, before I retired. They wanted everyone to know how to use the PC. But it was too different, and I was about to retire. I did do a little with the PC then, but not very much. But I still have the notes from those classes!

During the stage of her life in which she was working full-time, Hester relied on her employers to provide her with the training she needed to practice digital literacy. After Hester retired, she lost that technology support. As a result, Hester stopped using technology for more than a decade. This break in her digital practices relates to a break in her access to support services. The fact that Hester maintained all the notes from the computer classes she took in the 1960s, 1970s, and 1980s illustrates a desire to continue learning technology as it changed over time.

In any case, Hester started using technology again in the late 1990s, when she decided to purchase a digital camera so that she could take pictures at her granddaughter's wedding. She purchased the camera because a family member told her that she could take more pictures with the digital camera than she could on a conventional roll of film. She did not, however, find the support she felt she needed in order to learn how to use her digital camera within her family. She said that: 
I got it [the digital camera] just to take pictures and I wanted to take pictures of my granddaughter's wedding. But I could not figure out how to use it [laughs].

What to do with the pictures after I took them!

To address this learning need, Hester decided to seek support from her senior center. Hester joined a senior center shortly after she retired because the senior center was rooted in her local community. Many of Hester's now retired friends participated in the senior center. Furthermore, her mother was a leader in the senior center in the 1970s. This space, which already had played an important role in her life, began to also play a role in her digital learning practices:

I got some help from some university students [who volunteered in a computer class] here at the senior center. I figured out I better buy a computer so I had some place to put my pictures. [Laughs] I just didn't realize you needed a computer if you used a digital camera. [Laughs] They never tell you what all you need, and it seems like you always need something else. So, anyhow, I bought a desktop, with XP, in 2000, 2001, something like that. I can't remember exactly when. I still have that computer. It is at home. I still use it. But it is getting old. I guess I'm getting old too [laughs]. Some of the university students at the senior center helped me figure out how to use it.

Although Hester found some support in her senior center, it was not enough to enable her to do everything she wanted to do with technology. The volunteers Hester turned to for support were not always present at the senior center, and as a result Hester could not always find the support she wanted. After Hester started using her desktop computer (and later her laptop) to manage her digital photographs, she did not continue to learn how to do more things use these devices, despite desiring to do so. I asked Hester to 'tell me about what you have been doing with technology since' learning how to transfer the photos from her digital camera to her computer. She responded:

Not much. I was using my desktop a little bit, now and then, but less and less as time went on. The university students stopped coming to the senior center, I can't remember when, but sometime. And then without them here to ask questions, I guess I just used the computer less and less. Oh, I got on it from time to time. And I take pictures now and then with my digital camera .... It always changes. [Laughs] I guess that is how it is.

Nevertheless, Hester is not a passive user of technology support services created for her. When computer classes were discontinued at the senior center because of a lack of volunteers to staff them, Hester (and others at the senior center) requested over and over again that someone help them with technology. This persistence prompted the staff of the senior center to actively seek more volunteers for its computer classes.

\section{Digital learning produced through negotiations over information infrastructure}

The stories of the Tubman Senior Center and of Hester illustrate how community-based information infrastructure emerges through situated negotiations involving staff, volunteers, and older adults. Another area of negotiation in this infrastructure centered on what digital devices would be supported. Policies in the institutions compelled learners 
to use desktop computers provided by the institutions, and thus controlled by them. In contrast, many older adults sought assistance on the personal digital devices that they own. Both nationally (Smith 2014) and locally, older adults increasingly own their own digital devices (e.g. smartphones, tablets, digital cameras). Older adults bring these devices to senior centers and to public libraries to learn how to use them. In contrast, the institutions attempt to limit technology support only to those devices owned by the institutions, such as computer labs. In fact, during fieldwork I observed eleven instances of staff and volunteers refusing to assist older adults on the devices they own.

Negotiations over the boundaries of technology support services involve multiple actors working at multiple levels. For instance, since the late 2000s, one of the public libraries studied has had a program focused on helping patrons use eCollections (such as eBooks). The librarians that administer this program are aware that older adults are its primary audience. Promotional materials prominently feature images of older adults. Librarians are also aware that many of the older adults coming to the programs seek support learning to use their personal devices, and not only to access digital library collections. Nevertheless, on three occasions during fieldwork I observed older adults coming to these programs who sought general assistance with technology being turned away by librarians. On the first occasion, an older adult did not own a personal device, but wanted to learn more about tablet technology. On the second occasion, an older adult owned an iPad, but said she needed help getting started with it before learning to use eBooks. A third woman also went to an eCollections program with her new iPad to figure out how to use it. All three individuals were told by librarians that they would have to limit their participation in the programs around learning how to access the library's eCollections. This was because the administrators of this program wanted to limit its focus to content owned and managed by the library. The staff wanted to control the program. In contrast, older adults sought to adapt it to meet their needs.

Aware that the program was not meeting the needs of older adults, one librarian attempted to change the focus of the programs. In October 2014, this librarian attempted to re-brand the program as a 'drop-in technology help' program that would help older adults learn whatever they wanted to learn. The head of adult services at the library, however, rejected this proposal, and the restrictive focus on eCollections continues. Although in this particular instance change did not occur through these negotiations, through their agency older adults did pressure these institutions to attempt to change the program.

\section{Supportive relationships with technology support staff and volunteers}

An example of older adults successfully negotiating for change appears in instances of older adults forming supportive relationships that endure across time with the volunteers and staff that they find in public libraries and senior centers. As individuals, older adults exert their agency in this community-based information infrastructure by trying, and sometimes succeeding, to form relationships with the technology helpers they find there. Older adults rely on these relationships to learn technology across time. At one public library an older man referred to one of the technology volunteers as 'the one I always go to for help. She knows what I need.' I found similar relationships forming at all six institutions studied.

Older adults develop these relationships because it takes time to identify someone willing and able to provide ongoing technology support. Once such an individual is 
found, older adults return to them over and over again. At a public library, one staff member (whose official job title is children's librarian) said that for the last two years she has worked with an older woman who comes in every Monday afternoon to work with her to learn to use the computer:

I can't even remember how that started! She was just coming in all the time asking questions, and I guess after a while we just kind of settled into that routine. Now I know to leave some time on Monday afternoon free because I know she will be in with more questions [laughs].

Relationships of this sort emanate from the agency of older adults. This children's librarian started working with an older adult learning technology not because this type of task was part of her work responsibilities, but rather because older adults sought and insisted on this type of support.

Unfortunately, these relationships are not always supported or nurtured by the institutions in which they form. Librarians stated that these relationships emerge very regularly, but problems arise when a favored volunteer leaves and the patron becomes frustrated trying to find someone else who will work with them. As a result of this problem, one library tried to make technology support more anonymous. This library wants patrons to develop relationships with the library as an institution, and not with individual technology volunteers. To achieve this goal, the library has decided to not give volunteers name tags; technology volunteers simply wear a badge that says 'volunteer' on it. Nonetheless, older adults continue to endeavor to form ongoing relationships with technology helpers. The library wants technology support services to operate in one way (anonymised), older adults want them to operate in a different way (relationship-driven). Through situated negotiations technology support services emerge in these spaces.

\section{Older adults not only acquire information, they also provide it}

Technology support services in public libraries and senior centers are created and designed to provide members of the public with the support and information they need to successfully learn to use technology. However, older adults do not only acquire information through this community-based information infrastructure. They also sometimes provide staff and volunteers with information that enables them to learn something new about technology.

In the rapidly changing realm of consumer electronics, it is nearly impossible for any one individual to have mastery over all of the digital devices and platforms that exist in the world. In this context, technology support staff and volunteers frequently have to learn from older adults about their devices as they attempt to support their learning practices. The older adults that participated in this study own heterogeneous technologies. During fieldwork, laptops were brought in by 49 per cent of the older adults. Other devices brought include: tablets (29\%); smartphones (26\%); A/V devices (e.g. digital cameras and mp3 players, 19\%); flash-drives (17\%); flip-phones (8\%); and even printers $(1 \%)$. Many of the devices and software used by older adults were quite old. The oldest technology encountered during fieldwork was an Apple PowerBook from 1997, which the owner continues to use on a weekly basis to check her email. She brought the laptop to a senior center because she wanted help using it to browse the internet. 
Laptops, mp3 players, and digital cameras more than ten years old were also brought in for support. Some older adults also wanted help using programs like Microsoft Works and WordPerfect X3, software which has not been supported by its developers since 2007 and 2008, respectively.

While supporting older adults across diverse technologies and software, staff and volunteers learn more about the technology they encounter. In an email to me, one volunteer discussed a technology support session she had with an older adult at a public library: 'When she shared her method for creating and remembering passwords. I wrote it down and thanked her multiple times for the tip! It was really great .... We hugged at the end.' Older adults and those that help them in public libraries and senior centers learn technology together in the context of the ever-changing nature of technology released into the consumer marketplace.

\section{Contributions of older adults rendered invisible by ageism}

This article has highlighted and discussed the many ways that older adults seek to adapt and contribute to community-based information infrastructure. These contributions are rendered invisible, both to the institutions and to older adults themselves, because of societal ageism. Ageism refers to the stereotyping of and discrimination against individuals and groups on the basis of their age (Nelson 2004).

Ageist attitudes sometimes led staff to discontinue programs used by older adults. At a senior center the director complained that older adults use the computer lab for what she sees as trivial purposes. Discussing why technology support services were discontinued there before I started my fieldwork, she stated that 'just a few people used the technology, and they mostly just wanted to look up trivia for things like crossword puzzles. It just wasn't worth our time to continue the program.' She and other staff decided that what older adults do with technology is not important enough to support and foster. A similar incident occurred at one of the public libraries when a computers class was discontinued in December 2014, despite being very popular among older adults. In both cases, ageist assumptions about the digital literacy of older adults led to the cessation of technology support services used widely by local older adults.

Furthermore, when the administrators of these institutions create services for older adults, they do so through an ageist lens. At public libraries, the only services explicitly for older adults are 1) homebound book delivery services and 2) assistive technologies for people with disabilities. Both services frame older adulthood as a time of disability and decline. It is of course important that public libraries serve the disabled, but to conflate disability with old age is ageist.

Finally, all six institutions rely on young university students as technology volunteers, a structure that reinforces the idea that young people are the natural technology tutors of old people. This reinforcement is illustrated in one tech savvy older woman's discussion of why she does not help other older adults learning technology at her senior center:

I'm old! They [other older adults] don't want help from me! I get by with technology .... And if I get stuck I can figure it out. Usually. [Laughs] When it works, it works. But when it doesn't. [Laughs] Help someone else here at the center? No, no, no. That is for you [young people] to do. You know this stuff in and out. What could I add? 
The structure of relying on young technology tutors for older adults leads to bottlenecks when the number of older adults seeking support far exceeds the number of young people available to assist. During an average technology support session at the senior centers in which I participated, five older adults attended. In contrast, on average only two volunteers were available. Since older adults are socialised by the structure of the services, and by ageist ideas of youth and technology more generally, to seek support from a young person, this situation led to bottlenecks in which the supply of volunteers does not meet the demand. On especially busy days, when up to ten people came in for support from only two people, help sessions devolved into chaos as volunteers rushed from person to person, trying to make sure everyone received at least some support during the hour. In contrast, on one slow day at a senior center only one older adult showed up. She exclaimed: 'Thank God I have you to myself today!' Older adults appreciated when they did not have to compete for the time of young technology volunteers. This story illustrates how ageism is woven into this community-based information infrastructure. Older adults and young technology tutors play roles in this infrastructure in part shaped by social perceptions of ageing and technology.

\section{Discussion}

Through the processes analysed above, older adults learn technology in a communitybased information infrastructure. Older adults do not simply rely on services created for them. In diverse ways, older adults create, lead, and advocate for the technology support services they utilise. Information infrastructure reflects the ever-evolving relationship between information systems and information users (Star 1999). In community-based information infrastructure that relationship is shaped by negotiation and social struggle. The dominant tendencies discovered in this study, summarised above, co-exist alongside counter tendencies that could in the future become dominant, given the right support. For example, one counter tendency consists of older adults learning how to use new technologies alongside staff of public libraries and senior centers also learning how to use them. By making these counter tendencies visible against the ageist tendency to render them invisible, this study showcases the agency of older adults and staff creatively reconfiguring senior centers and public libraries to better support the digital learning of all.

The incorporation of digital technology into community life also affects the social shaping of older adulthood. As a result of the disruptions of the still-emergent information society, older adults are recast by these institutions from community leaders to passive service recipients who receive help with technology from individuals thirty to seventy years younger than themselves. This structure reinforces ageist ideas about the supposedly limited capacity of older adults in the information society. Through its practices and policies, the community-based information infrastructure contributes to shaping both how older adults see themselves and how society sees older adulthood. Ageism is deeply ingrained in community-based information infrastructure, older adult digital literacy, and society more generally. Ageism affects how we study older adulthood, as discussed by Bowen (2012) and Gurstein (2012), and it further affects how older adults are framed in the policies and practices of senior centers and public libraries.

Nevertheless, older adults do not simply use services created for them. By seeking support on their own devices (even when staff resist this trend), and by organising to 
create and to sustain senior centers in relation to the invisibility of older adulthood in other public spaces, older adults actively shape information infrastructure to meet their needs. By better understanding and being open to the agency of older adults, public libraries, senior centers, and other community-based information infrastructure could find they could do more by empowering older adults to contribute to their communities.

\section{Conclusions}

The information society is also an ageing society. This means that as digital technology becomes densely woven into the fabric of everyday life, the median age of humanity continues to rise. The participation of older adults in the information society is often seen as dependent on how they cope with their supposedly declining minds and bodies. This study reframes this phenomenon by studying the digital literacy and learning of older adults in the context of the communities where they live.

The digital literacy of older adults is shaped by the relative supportiveness of the information infrastructure in their communities. The relative supportiveness of this infrastructure is, in turn, shaped by older adults themselves. Through negotiations and struggles, large and small, older adults contribute to these institutions over time. Older adults actively endeavor to contribute to this infrastructure, even though the staff responsible for administering it do not always recognise or support their agency. Public libraries and senior centers are overpressured, publicly funded institutions. By embracing the agency of older adults, these institutions, and others like them elsewhere in the world, could reconfigure themselves for an information society that is also ageing. More generally, by learning to embrace and nurture the agency of older adults, local communities could create a more inclusive information society.

\section{Notes}

1. More details on the methods of this study can be found in Lenstra (2016).

2. No age-based definition of 'older adult' was used in this study. Instead, I relied upon self-identifications. That is, individuals self-identified as 'older' by participating in these technology support services and in this study.

3. To protect the privacy of individuals and institutions, all names in this article are pseudonyms.

\section{References}

American Library Association (2015). ALA Library Fact Sheet 1. http://www.ala.org/tools/libfactsheets/ alalibraryfactsheet01. (Accessed August 29, 2016).

Bailey, Arlene, \& Ngwenyama, Ojelanki (2011). The Challenge of E-participation in the Digital City: Exploring Generational Influences Among Community Telecentre Users. Telematics and Informatics, 28(3): 204-214.

Bennett-Kapusniak, Renee (2013). Older Adults and the Public Library: The Impact of the Boomer Generation. Public Library Quarterly, 32(3): 204-222.

Blomberg, Jeanette \& Karasti, Helena (2013). Reflections on 25 Years of Ethnography in CSCW. Computer Supported Cooperative Work (CSCW), 22(4-6): 373-423.

Bowen, Lauren Marshall; Arko, Kirsti; Beatty, Joel; Delaney, Cindy; Dorpenyo, Isidore; Moeller, Laura; Roberts, Elsa \& Velat, John (2014). Community Engagement in a Graduate-Level Community Literacy Course. Community Literacy Journal, 9(1): 18-38.

Bowen, Marshall Lauren (2012). Beyond Repair: Literacy, Technology, and a Curriculum of Aging. College English, 74(5): 437-457.

Bowker, Geoffrey C. (1994). Science on the Run: Information Management and Industrial Geophysics at Schlumberger, 1920-1940. Cambridge: MIT press. 
Bowker, Geoffrey C. \& Star, Leigh Susan (1999). Sorting Things Out: Classification and its Consequences. Cambridge: MIT Press.

Cohen, Rennie (2003). Foreword, pp. ix-xi in Beisgen, Beverly \& Kraitchman, Marilyn (eds.) Senior Centers: Opportunities for Successful Aging. New York: Springer.

D’Angelo, Ed (2006). Barbarians at the Gates of the Public Library: How Postmodern Consumer Capitalism Threatens Democracy, Civil Education and the Public Good. Sacramento, Calif.: Library Juice Press.

Edwards, Paul N; Jackson, Steven J; Bowker, Geoffrey C \& Williams, Robin (2009). Introduction: An Agenda for Infrastructure Studies. Journal of the Association for Information Systems, 10(5): 364-374.

Gardner, Paula J; Kamber, Tom \& Netherland, Julie (2012). Getting Turned On: Using ICT Training to Promote Active Ageing In New York City. The Journal of Community Informatics, 8(1): http://ci-journal. net/index.php/ciej/article/view/809/907.

Guribye, Frode (2015). From Artifacts to Infrastructures in Studies of Learning Practices. Mind, Culture, and Activity, 22(2): 184-198.

Gurstein, Michael (2012). Community Informatics and Older Persons: The Necessary Connection. The Journal of Community Informatics, 8(1): http://ci-journal.net/index.php/ciej/article/view/916.

Hardill, Irene (2014). The Intergenerational Help Desk: Encouraging ICT Use in Older Adults in England, pp. 273-285 in Vanderbeck, Robert \& Worth, Nancy (eds.) Intergenerational Space. London: Routledge.

Lamb, Roberta \& Kling, Rob (2003). Reconceptualizing Users as Social Actors in Information Systems Research. MIS Quarterly, 27(2): 197-236.

Lenstra, Noah (2016). The Community Informatics of an Aging Society: A Comparative Case Study of Senior Centers and Public Libraries. (Doctoral dissertation, University of Illinois).

National Council on Aging. (2014). 'Senior Centers: Fact Sheet'. https://www.ncoa.org/resources/fact-sheetsenior-centers/. (Accessed August 29, 2016).

McKee, Heidi \& Blair, Kristine (2006). Older Adults and Community-Based Technological Literacy Programs: Barriers \& Benefits to Learning. Community Literacy Journal, 1(2): 13-39.

Nelson, Todd D. (2004). Ageism: Stereotyping and Prejudice against Older Persons. Cambridge, MA: MIT Press.

Oudshoorn, Nelly, \& Pinch, Trevor J. (2003). How Users Matter: The Co-Construction of Users and Technologies. Cambridge, MA: MIT Press.

Perry, Claudia A. (2014). Information Services to Older Adults: Initial Findings from a Survey of Suburban Libraries. The Library Quarterly, 84(3): 348-386.

Sayago, Sergio, \& Blat, Josep (2010). Telling the Story of Older People E-mailing: An Ethnographical Study. International Journal of Human-Computer Studies, 68(1): 105-120.

Schull, Diantha D. (2013). 50+ Library Services: Innovation in Action. Chicago: American Library Association.

Selwyn, Neil (2004). The Information Aged: A Qualitative Study of Older Adults' Use of Information and Communications Technology. Journal of Aging Studies, 18(4): 369-384.

Smith, Aaron (2014). Older Adults and Technology Use. Pew Research Center.

http://www.pewinternet.org/2014/04/03/older-adults-and-technology-use/. (Accessed August 29, 2016).

Star, Susan L. (1999). The Ethnography of Infrastructure. American Behavioral Scientist, 43(3): 377-391.

Star, Susan L. \& Griesemer, James R. (1989). Institutional Ecology, 'Translations' and Boundary Objects: Amateurs and Professionals in Berkeley's Museum of Vertebrate Zoology, 1907-39. Social Studies of Science, 19(3): 387-420.

Suchman, Lucy A. (1987). Plans and Situated Actions: The Problem of Human-Machine Communication. Cambridge, UK: Cambridge University Press.

Xie, Bo. (2005). Getting Older Adults Online: The Experiences of SeniorNet (USA) and OldKids (China), pp. 175-204 in Jaeger, Birgit (ed.) Young Technologies in Old Hands: An International View on Senior Citizens' Utilization of ICT. Copenhagen: DJVF Publishing. 